\title{
Gender Equity \& Its Relation to Female Genital Mutilation in Rural Minia, Egypt
}

Mohammed ES, Seedhom AE* and Mahfouz EM Department of Public Health and Preventive Medicine, Minia University, Egypt

*Corresponding author: Seedhom AE, Department of Public Health and Preventive Medicine, Minia University, Minia 61111, Egypt

Received: December 26, 2016; Accepted: February 28, 2017; Published: March 02, 2017

\author{
Abstract \\ Objectives: To measure and relate Gender Equity Score (GES) to FGM \\ future intentions.
}

Methods: A cross-sectional community-based study. An interview administered questionnaire was used to measure GES. A systematic random sample was taken from the village. 578 males and females were included in the period from October to December 2016.

Results: Men were more supportive of FGM. $78.03 \%$ of rural dwellers had low GES, $17.3 \%$ had medium and $4.67 \%$ had high GES. There was a significant relation between GES, supporting attitude towards FGM ( $p=0.001)$, Knowledge that FGM is harmful $(p=0.03)$ and future intention to undergo to their daughters $(p=0.0001)$.

Conclusion: The association between low GES, education, social pressure and intentions to carry out FGM to their daughters means that could help to fight FGM increasing importance of values as personal wellbeing and women empowerment.

Keywords: Female genital mutilation; Gender equity; Egypt

\section{Abbreviations}

FGM: Female Genital Mutilation; GES: Gender Equity Score; EHIS: Egyptian Health Issues Survey; EDHS: Egypt Demographic Health Survey

\section{Introduction}

World bodies have defined gender equality in terms of human rights, especially women's rights, and economic development [1]. UNICEF describes that gender equality "means that women and men", and girls and boys, enjoy the same rights, resources, opportunities and protections. It does not require that girls and boys, or women and men, be the same, or that they be treated exactly alike [2].

The United Nations Population Fund stated that, "despite many international agreements affirming their human rights, women are still much more likely than men to be poor and illiterate. They have less access to property ownership, credit, training and employment. They are far less likely than men to be politically active and far more likely to be victims of domestic violence [3].

Thus, promoting gender equality is seen as an encouragement to greater economic prosperity. For example, nations of the Arab world that deny equality of opportunity to women were warned in a 2008 United Nations-sponsored report that this disempowerment is a critical factor crippling these nations' return to the first rank of global leaders in commerce, learning, and culture [4].

A large and growing body of research has shown how gender inequality undermines health and development. To overcome gender inequality the United Nations Population Fund states that, "Women's empowerment and gender equality" requires strategic interventions at all levels of programming and policy-making. These levels include reproductive health, economic empowerment, educational empowerment and political empowerment [5].

Female genital mutilation is mostly carried out on girls between the ages of 0 and 15 years. However, occasionally, adult and married women are also subjected to the procedure. The age at which female genital mutilation is performed varies with local traditions and circumstances, but is decreasing in some countries [6].

In every society in which it is practiced, female genital mutilation is a manifestation of gender inequality that is deeply entrenched in social, economic and political structures. Such practice has the effect of perpetuating normative gender roles that are unequal and harm women. Analysis of international health data shows a close link between women's ability to exercise control over their lives and their belief that female genital mutilation should be ended [7].

\section{Subjects and Methods}

A cross-sectional community-based study was conducted to measure gender equity score and identify its association with FGM in a rural area in Minia governorate that was chosen randomly then a systematic random sample was taken from the village (the $1^{\text {st }}$ house was chosen randomly then every $5^{\text {th }}$ house).

The questionnaires were administered, face to face. The sample size was calculated using EP Info version 2000. A total of 578 male and female rural dwellers, aged $>18$ years were participated in this study.

The study was conducted in the period from October to December, 2016. A pilot study was performed on 50 persons and the 
questionnaire was further validated through a review panel process where each item was considered for appropriateness.

GES was used. The 2006 Victorian Survey identified that the strongest predictor for holding violence-supportive views about violence against women was an individual's 'gender equity score [17]. This gender equity score or GES was constructed by asking respondents a series of attitudinal statements about women and their role in society. As with the 2006 Victorian Survey, the 2009 National Survey asked participants to respond to the same series of attitudinal statements relating to gender equity adapted from [18]. Responses to these statements were based on a likert scale where $1=$ 'strongly agree' and $5=$ 'strongly disagree'. The questions were:

On the whole, men make better political leaders than women.

When jobs are scarce men should have more right to a job than women.

1. A university education is more important for a boy than a girl

2. A woman has to have children to be fulfilled

3. It's OK for a woman to have a child as a single parent and not want a stable relationship with a man (reversed scored)

4. In the 2009 survey additional three statements were included:

5. Discrimination against women is no longer a problem in the workplace

6. Men should take control in relationships and be the head of the household

7. Women prefer a man to be in charge of the relationship

The gender equity scale and associated scores were calculated and summed to give a score out of 100. Participants were required to respond to eight statements on a scale of 1 (strongly agree) to 5 (strongly disagree).

The eight statements were summed to give the respondent a score out of 40 . The score was then multiplied by 2.5 to give the respondent a score out of 100 . The score out of 100 was then categorized as 'high GES' (>90), 'medium GES' (75-90) or 'low GES' (<75).

Those who scored closest to 100 gave answers to the statements which indicated they supported gender equity - women should not only have equal rights and opportunities but be treated fairly and justly in the distribution of benefits and responsibilities between women and men. Those who scored lower on the gender equity scale expressed views that indicated less support for women being treated equally and fairly [8].

\section{Statistical analysis}

The Statistical Program SPSS for windows version 20 had been used in data analysis. Statistical significance was set at $\mathrm{p}<0.05$.

\section{Ethical considerations}

The study protocol had been approved by the standard ethics of Minia University ethical committee for human studies. Interviews were held in strict privacy, mainly in the respondents' homes, with no one able to overhear the conversation. The participants were informed about their possibility to withdraw at any point during the research phase and gave written informed consent to participate.

\section{Results}

The study highlighted the key characteristics that either foster or discourage the continuation of the practice. A total of 578 rural dwellers were included in the present study with only $0.1 \%$ non response rate. Respondents' average age was $30.7 \pm 12.4$ years. $89.6 \%$ were moslems in religion and $68.9 \%$ were women. $59.2 \%$ were married (Table 1).

Table 2 showed that $451(78.03 \%)$ of rural dwellers had low GES, $100(17.3 \%)$ had medium and 27 (4.67) had high GES.

Table 3 showed that there was a significant relation between GES and sex, marital status and education. Also, there was a significant relation between GES and attitude that FGM is a good practice $(\mathrm{p}=0.0001)$, Knowledge that FGM is harmful $(\mathrm{p}=0.02)$ and agreement with FGM performance to daughter in the future $(\mathrm{p}=0.0001)$.

\section{Discussion}

FGM has gained increased attention in policy and research over the last decades due to its impact on women's health, including severe violation of human rights $[9,10]$. Studies on FGM in the general population in Egypt have reported that almost all Egyptian women (97\%) have been subjected to FGM $[11,12]$.

About $78.03 \%$ of rural dwellers had low GES, this result was less than what was found by Hassan et al. who found that $90.5 \%$ of respondents' scores fell within the low range of support for gender

\begin{tabular}{|c|c|c|}
\hline Percentage & Frequency & Socio-demographic variables \\
\hline & & Sex \\
\hline 31.1 & 180 & Male \\
\hline \multirow[t]{2}{*}{68.9} & 398 & Female \\
\hline & & Age \\
\hline \multicolumn{2}{|c|}{$18-74(30.7 \pm 12.4)$} & Range (Mean $\pm S D$ ) \\
\hline & & Educational level \\
\hline 17.3 & 100 & Illiterate \\
\hline 9.3 & 54 & Read and write \\
\hline 10.7 & 62 & 1ry education \\
\hline 28.4 & 164 & $2^{\text {nd }}$ education \\
\hline \multirow[t]{2}{*}{34.3} & 198 & University \\
\hline & & Religion \\
\hline 89.6 & 518 & Moslem \\
\hline \multirow[t]{2}{*}{10.4} & 60 & Christian \\
\hline & & Marital status \\
\hline 36.7 & 212 & Single \\
\hline 59.2 & 342 & Married \\
\hline 0.6 & 4 & Divorced \\
\hline 3.5 & 20 & Widow \\
\hline 100 & 578 & Total \\
\hline
\end{tabular}


Table 2: Gender equity score among the studied sample.

\begin{tabular}{|c|c|c|}
\hline GES & No. & $\%$ \\
\hline Low & 451 & 78.03 \\
\hline Middle & 100 & 17.3 \\
\hline High & 27 & 4.67 \\
\hline
\end{tabular}

Table 3: Relation between GES and socio-demographic variables and some factors related to FGM, rural Minia, Egypt.

\begin{tabular}{|c|c|c|c|c|}
\hline \multirow[t]{2}{*}{$x^{2}$} & Total & Low GES & $\begin{array}{l}\text { High and } \\
\text { medium GES }\end{array}$ & \\
\hline & & & $(n=127)$ & \\
\hline \multirow[t]{2}{*}{$p$ value } & $(n=578)$ & $(n=451)$ & & \\
\hline & & & & Sex \\
\hline 24.3 & $398(67.6)$ & $333(72.8)$ & $65(51)$ & Females \\
\hline \multirow[t]{2}{*}{0.0001} & $180(32.4)$ & $118(27.2)$ & $62(49)$ & Males \\
\hline & & & & Age \\
\hline 2.4 & $286(49.5)$ & $215(47.8)$ & $71(55.1)$ & Less than 25 year \\
\hline \multirow[t]{2}{*}{0.1} & $292(50.5)$ & $236(52.2)$ & $56(44.9)$ & More than 25 year \\
\hline & & & & Marital status \\
\hline 8.4 & $232(40.8)$ & $167(37.6)$ & $65(51)$ & Never married \\
\hline \multirow[t]{2}{*}{0.004} & $346(59.2)$ & $19(62.4)$ & $62(49)$ & Ever married \\
\hline & & & & Education \\
\hline 48.4 & $218(38.5)$ & $137(31.2)$ & $81(61.9)$ & University \\
\hline \multirow[t]{5}{*}{0.0001} & $144(26.5)$ & $136(31)$ & $8(12.2)$ & Secondary education \\
\hline & $32(8.4)$ & $30(8.5)$ & $2(8.2)$ & Primary education \\
\hline & $44(10.4)$ & $42(11)$ & $2(8.2)$ & Read and write \\
\hline & $100(16.2)$ & 86 (18.3) & $14(9.5)$ & Illiterate \\
\hline & & & & $\begin{array}{l}\text { Attitude that FGM is a good } \\
\text { practice }\end{array}$ \\
\hline 17.5 & $262(45.6)$ & $227(50.3)$ & $35(30.6)$ & Yes \\
\hline \multirow[t]{2}{*}{0.0001} & $316(54.4)$ & $224(49.7)$ & $92(69.4)$ & No \\
\hline & & & & $\begin{array}{l}\text { Knowledge that FGM is } \\
\text { harmful }\end{array}$ \\
\hline 5.1 & $304(52.4)$ & 225 (49.9) & $79(60.5)$ & Yes \\
\hline \multirow[t]{3}{*}{0.02} & $274(47.6)$ & $226(50.1)$ & $48(39.5)$ & No \\
\hline & & & & $\begin{array}{l}\text { Agree to perform FGM to his } \\
\text { daughter in the future }\end{array}$ \\
\hline & & & & Yes \\
\hline 31.7 & $315(54.2)$ & $275(60.5)$ & 40 (34) & No \\
\hline 0.0001 & $263(45.8)$ & $176(39.5)$ & $87(66)$ & \\
\hline
\end{tabular}

equity, $8.6 \%$ fell within the medium range of support. This difference may be explained by that, our study sample included males and females, while in the other study, the participants were males only and this emphasize that women in poor agricultural villages in Upper Egypt were still considered to be inferior to males and to their husbands [13].

Behaviour change will become more likely when people are not only ready to change, but willing and able as well. Such interpretation is consistent with social convention theory. Social conventions require social support. To change social conventions, role models (such as individuals or families in good social standing) may introduce new behaviours [14].
In an analysis to EDHS, 2008 in Egypt, unlike mother's education; father's education as well as father employment status had no association with FGM. In addition, the parent's preference for daughter circumcision decreased over time [15].

According to the results of a previous study, higher educated mothers were less likely to have circumcised daughters than for medium and low educated women when other factors as family and community factors were held constant. Past experience of women about FGM was also consistently related to decision to mutilate their daughters since mutilated women were more likely to have their daughters circumcised too. Women who believed that hygiene and cleanness were benefits for girls who undergo FGM were more likely to mutilate daughter. Family approval, achievement of community status and tradition and sexual control, assurance of eligibility for marriage and male pleasure were other factors that might contribute to fostering the FGM practice [16].

\section{Limitations of the Study}

1. This cross-sectional study allowed studying associations but not causality.

2. Some women and men refused to participate in the study. Applying patience and diplomacy the researchers had to work for long hours.

3. The possibility of recall bias or reporting bias.

\section{Conclusion and Recommendations}

The overall results gave important inputs to policy makers. Educating and protecting girls and increasing importance of values as personal wellbeing, health care and women empowerment which could help to fight acceptance of FGM.

\section{Acknowledgement}

We are grateful for all the women and men of Burgaia village, Minia, Egypt, for their participation in the study.

\section{Ethical Consideration}

This research took approval from the research ethical committee of the university. All participants gave consent to participate in the study.

\section{References}

1. World Bank. "Gender Equality as Smart Economics". A World Bank Group Gender Action Plan. 2017.

2. UNICEF. "Promoting Gender Equality: An Equity-based Approach to Programming".

3. "Gender equality - UNFPA - United Nations Population Fund". 2015.

4. Gender equality in Arab world critical for progress and prosperity, UN report warns E-joussour. 2008.

5. UNFPA. "Engaging Men and Boys: A Brief Summary of UNFPA Experience and Lessons Learned".

6. UNICEF. Female genital mutilation/female genital cutting: a statistical report. New York, UNICEF. 2005.

7. Changing a harmful social convention: female genital mutilation/cutting. Innocenti Digest. Florence, UNICEF. 2005.

8. McGregor K. National Community Attitudes towards Violence against Women Survey. A Full Technical Report, Australian Institute of Criminology, Canberra. 2009. 
9. Schroeder P. Female genital mutilation - a form of child abuse. N Engl J Med 1994; 331: 739-740.

10. World Health Organization. Female genital mutilation Geneva: WHO. 2014.

11. Yount KM. Like mother, like daughter? Female genital cutting in Minia, Egypt. J Health Soc Behav. 2002: 43; 336-358.

12. El Zanaty FH, Way AA. Egypt Interim Demographic and Health Survey. Ministry of Health and Population. 2004.

13. Hassan E, Seedhom A, Mahfouz E. Men's Perception of Domestic Violence, Rural Minia, Egypt. Open Journal of Preventive Medicine. 2016: 06; 106-114.
14. Van Rossem R, Meekers D, Gage AJ. Women's position and attitudes towards female genital mutilation in Egypt: A secondary analysis of the Egypt demographic and health surveys, 1995-2014. BMC Public Health. 2025: 15; 874.

15. Saleh Z. Female Genital Mutilation in Egypt. A paper presented to the faculty of University of North Carolina at Chapel Hill. 2013.

16. Farina P, Elisa Ortensi L. Mother to daughter transmission of Female Genital Cutting in Egypt, Burkina Faso and Senegal. African Population Studies. 2014; 28: 1119-1131.
Austin J Public Health Epidemiol - Volume 4 Issue 1 - 2017

ISSN : 2381-9014 | www.austinpublishing group.com

Seedhom et al. () All rights are reserved
Citation: Mohammed ES, Seedhom AE and Mahfouz EM. Gender Equity \& Its Relation to Female Genital Mutilation in Rural Minia, Egypt. Austin J Public Health Epidemiol. 2017; 4(1): 1056. 